\title{
Leishmania mexicana
}

National Cancer Institute

\section{Source}

National Cancer Institute. Leishmania mexicana. NCI Thesaurus. Code C123510.

A species of parasitic trypanosomatid protozoa in the family Trypanosomatidae. L. mexicana is endemic in South and Central America and causes the mildest form of leishmaniasis. 